\title{
Prediabetes Directly Deteriorates into Diabetic Ketoacidosis and Hyperosmolar Hyperglycemic Syndrome Triggered by Acute Pancreatitis: A Case Report Illustrating a "Chicken and Egg" Paradigm in Ketosis-Prone Diabetes
}

Runbo Song $\cdot$ Shanjin Cao

Received: February 19, 2018 / Published online: March 29, 2018

(C) The Author(s) 2018

\section{ABSTRACT}

Introduction: Diabetic crises occur most often in patients with type 1 diabetes and occasionally in type 2 diabetes, especially under stressful conditions. However, a diabetic crisis occurring directly from prediabetes is an unusual phenomenon.

Case Report: A 45-year-old woman presented with postprandial left upper quadrant abdominal pain, nausea, and vomiting. She had a past medical history of prediabetes with impaired fasting glucose and HbA1c 6.4\%. On admission, routine laboratory tests showed high anion gap metabolic acidosis ( $\mathrm{pH}$ 6.92), anion gap $41 \mathrm{mmol} / \mathrm{L}$, blood glucose $931 \mathrm{mg} / \mathrm{dL}$, beta-

Enhanced content To view enhanced content for this article go to https://doi.org/10.6084/m9.figshare. 6004994 .

\section{R. Song}

Department of General Surgery, Shijiazhuang 3rd Hospital, 15 Tiyu South Street, Changan District, Shijiazhuang 050000, Hebei, China

S. Cao $(\bowtie)$

Department of Hospitalist, St. Anne's Hospital, 795

Middle Street, Fall River, MA 02721, USA

e-mail: scao@prima-care.com

S. Cao

PrimaCARE, P.C., 277 Pleasant Street, Fall River, MA 02721, USA hydroxybutyrate $28 \mathrm{mmol} / \mathrm{L}$, and calculated effective osmolarity $322 \mathrm{mOsm} / \mathrm{kg}$; she was diagnosed with diabetic ketoacidosis (DKA) and hyperosmolar hyperglycemic syndrome (HHS), and DKA-related abdominal pain. Later, the patient was found to have elevated lipase and amylase, and diagnosed with acute pancreatitis. Since DKA can induce abdominal pain and nonspecific lipase elevation, both of which are characteristics of acute pancreatitis, while acute pancreatitis can conversely trigger DKA, there exists a "chicken and egg" paradigm. Therefore, the differential diagnosis is discussed.

Conclusion: It is important to differentiate DKA from concomitant causes of abdominal pain to avoid missing the underlying etiology, which can be the trigger for DKA. During diabetic crises, treating the underlying trigger is just as important as managing metabolic derangements in order to achieve favorable outcomes; meanwhile, managing acute pancreatitis-associated hyperglycemia can promote recovery. Additionally, diabetic crisis that directly evolves from prediabetes illustrates an atypical form of diabetes called ketosis-prone diabetes; we briefly discuss its clinical characteristics, classification, and follow-up.

Keywords: Acute pancreatitis; Diabetic crisis; Diabetic ketoacidosis; Hyperosmolar hyperglycemic syndrome; Ketosis-prone diabetes; Prediabetes 


\section{INTRODUCTION}

Diabetic crises, including diabetic ketoacidosis (DKA) and hyperosmolar hyperglycemic syndrome (HHS), occur most often in patients with type 1 diabetes and occasionally in patients with type 2 diabetes, especially under stressful conditions. The common precipitating factors include infection (e.g., pneumonia and urinary tract infection), medication noncompliance, myocardial infarction, stroke, acute pancreatitis, major surgery, trauma, and other unidentified factors $[1,2]$. The metabolic derangements result from the combination of relative or absolute insulin deficiency, increased levels of counter-regulatory hormones, and insulin resistance. DKA and HHS can also evolve directly from prediabetes, which is a less recognized clinical situation, indicating the presence of an atypical type of diabetes called ketosis-prone diabetes [3].

\section{CASE REPORT}

A 45-year-old Caucasian woman presented with abdominal pain, nausea, and vomiting for $17 \mathrm{~h}$. At $22 \mathrm{~h}$ prior to admission, she went out to dinner and drank one glass of wine. A few hours after the meal, she developed epigastric and left upper quadrant abdominal pain that was moderate, persistent, cramping, and aching; the pain radiated to her left middle back and arm without exacerbating or alleviating factors. The pain was associated with nausea, vomiting, and she could not tolerate any oral intake. She felt thirsty and had polyuria and positional lightheadedness. She reported no fever, chills, chest pain, cough, sputum production, dysuria, hematuria, diarrhea, hematochezia, and melena.

On further questioning, the patient shared that she had a history of gestational glucose intolerance 6 years ago, and has had occasional impaired fasting glucose of $81-107 \mathrm{mg} / \mathrm{dL}$ for the past 6 years. She began following an American Diabetes Association (ADA) diet 2 years ago and lost $25 \mathrm{lb}$. Additionally, she had a past medical history of supraventricular tachycardia, irritable bowel syndrome, social alcohol use, cholecystectomy, and thyroid papillary adenocarcinoma status post partial thyroidectomy complicated by postsurgical hypothyroidism. Home medications included metoprolol tartrate, levothyroxine, and meloxicam. The patient reported no family history of diabetes.

\section{Vital Signs on Admission}

Temperature $97.7^{\circ} \mathrm{F}$, pulse $130 \mathrm{bpm}$, respiratory rate $28 \mathrm{bpm}, \mathrm{BP} 134 / 71 \mathrm{mmHg}$, weight $87 \mathrm{~kg}$, height $1.68 \mathrm{~m}, \mathrm{BMI} 31 \mathrm{~kg} / \mathrm{m}^{2}, \mathrm{SpO}_{2} 99 \%$ on room air.

\section{Physical Exam}

The patient was in moderate distress. There was no acanthosis nigricans. Cardiovascular system revealed tachycardia. A pulmonary exam revealed tachypnea, accessory muscle usage with moderate respiratory distress. Abdominal exam revealed central obesity, normoactive bowel sounds, left upper quadrant and epigastric tenderness to palpation, no rigidity or guarding. No costovertebral angle tenderness.

\section{Laboratory Results}

CBC: WBC $25.9 \times 10^{9} / \mathrm{L}$, hemoglobin $14.7 \mathrm{~g} /$ $\mathrm{dL}$, hematocrit $45.8 \%$, platelet $386 \times 10^{9} / \mathrm{L}$, MCV $100.2 \mu \mathrm{m}^{3}$. BMP: sodium $135 \mathrm{mmol} / \mathrm{L}$, potassium $7.4 \mathrm{mmol} / \mathrm{L}$, chloride $89 \mathrm{mmol} / \mathrm{L}$, bicarbonate $5 \mathrm{mmol} / \mathrm{L}$, BUN $37 \mathrm{mg} / \mathrm{dL}$, creatinine $1.27 \mathrm{mg} / \mathrm{dL}$, glucose $931 \mathrm{mg} / \mathrm{dL}$, eGFR $46 \mathrm{~mL} / \mathrm{min}$.

Liver chemistry: Total bilirubin $0.2 \mathrm{mg} / \mathrm{dL}$, AST $23 \mathrm{U} / \mathrm{L}$, ALT $54 \mathrm{U} / \mathrm{L}$, ALP $138 \mathrm{U} / \mathrm{L}$, total protein $7.5 \mathrm{~g} / \mathrm{dL}$, albumin $4.5 \mathrm{~g} / \mathrm{dL}$. Calcium $8.7 \mathrm{mg} / \mathrm{dL}$, phosphate $1.4 \mathrm{mg} / \mathrm{dL}$, magnesium $2.1 \mathrm{mg} / \mathrm{dL}$. VBG: pH 6.92. Repeated ABG 2 h later: $\mathrm{pH} 7.21$, $\mathrm{pCO}_{2} 16 \mathrm{mmHg}, \quad \mathrm{pO}_{2} 129 \mathrm{mmHg}, \mathrm{HCO}_{3}{ }^{-}$ $6.4 \mathrm{mmol} / \mathrm{L}, \mathrm{SaO}_{2} 98 \%$ on $2 \mathrm{~L} / \mathrm{min}$ oxygen by nasal cannula. Beta-hydroxybutyrate $28 \mathrm{mmol} /$ $\mathrm{L}$, lactic acid $4.0 \mathrm{mmol} / \mathrm{L}$. Urinalysis showed urine ketones $80 \mathrm{mg} / \mathrm{dL}$, leukocyte esterase negative, urine culture no growth. HbA1c 6.4\%. Lipid profile: triglycerides $89 \mathrm{mg} / \mathrm{dL}$, total cholesterol $144 \mathrm{mg} / \mathrm{dL}$, LDL $91 \mathrm{mg} / \mathrm{dL}, \mathrm{HDL}$ 
$35 \mathrm{mg} / \mathrm{dL}$. TSH $3.12 \mathrm{mIU} / \mathrm{mL}$, free T4 $1.26 \mathrm{ng} /$ dL. Troponin I $<0.01 \mathrm{ng} / \mathrm{mL}$.

\section{Imaging Studies}

Ultrasonography of the abdomen revealed mild hepatic steatosis, incidental mild to moderate right-sided hydronephrosis, status post cholecystectomy. ECG on admission: sinus rhythm, HR $126 \mathrm{bpm}$, peaked $\mathrm{T}$ waves at lead V2-V6 consistent with hyperkalemia, no ischemic changes.

All procedures performed in this study were in compliance with the ethical standards of the institutional and/or national research committee and with the 1964 Declaration of Helsinki and its later amendments or comparable ethical standards. Informed consent was obtained from the individual participant for being included in the study.

\section{DISCUSSION}

The patient presented with severe anion gap metabolic acidosis, anion gap of $41 \mathrm{mmol} / \mathrm{L}$ $\left(\mathrm{Na}^{+}-\mathrm{Cl}^{-}-\mathrm{HCO}_{3}{ }^{-}\right)$and an albumin-corrected anion gap of $40 \mathrm{mmol} / \mathrm{L}$ [anion gap $-2.5 \times(4-$ albumin $)]$. This patient's high anion gap metabolic acidosis is likely primarily caused by DKA, with some contribution from the DKA-associated secondary lactic acidosis and volume depletion-induced pre-renal uremic acidosis.

Using Winter's formula $\left[\mathrm{pCO}_{2}=(1.5 \times\right.$ $\left.\mathrm{HCO}_{3}{ }^{-}\right)+8 \pm 2$ ], we calculated the respiratory compensation to yield an expected $\mathrm{pCO}_{2}$ between 15.6 and $19.6 \mathrm{mmHg}$. ABG revealed a $\mathrm{pCO}_{2}$ of $16 \mathrm{mmHg}$, suggesting she had a primary metabolic acidosis with adequate respiratory compensation.

The delta gap was used to investigate the presence of a mixed metabolic acid-base disorder. The normal range of delta gap is from -6 to +6 . If the delta gap is significantly positive $(>+6)$, a concomitant primary metabolic alkalosis is usually present; conversely, if the delta gap is significantly negative $(<-6)$, then a superimposed non-anion gap metabolic acidosis is usually present [4]. In our case, the delta gap [(adjusted anion gap - 12) - (24$\left.\left.\mathrm{HCO}_{3}{ }^{-}\right)\right]$of $+9 \mathrm{mmol} / \mathrm{L}$ indicated there was a co-existing primary metabolic alkalosis.

Meanwhile, the calculated effective osmolality $(2 \times \mathrm{Na}+$ glucose $/ 18)$ was $322 \mathrm{mOsm} / \mathrm{kg}$; thus, the patient also had HHS [1].

The underlying mechanism for the co-existing primary metabolic alkalosis and HHS is likely due to severe hyperglycemia-related glycosuria as well as ketoacidosis-associated osmotic diuresis causing volume depletion. In addition, her nausea, vomiting, and poor oral tolerance worsened her dehydration, thereby causing a contraction alkalosis [5] and the development of hyperosmolarity [1].

Taken together, this patient was diagnosed with DKA and HHS on admission and was triaged into the ICU and started on IV fluids, IV bicarbonate, and IV insulin drip, in accordance with diabetes crisis management guidelines [1]. Of note, the patient also presented with severe hyperkalemia with ECG changes. Hyperkalemia is a common finding in DKA, and is secondary to hypoinsulinemia and renal dysfunction (e.g., acute kidney injury in this case); the hyperkalemia is not due to the previously held opinion that metabolic acidosis causes the exchange of hydrogen ions for potassium ions across cell membranes [6, 7]. The severe anion gap acidosis was corrected by the second day of admission with repeat $\mathrm{ABG}$ showing $\mathrm{pH}$ 7.42, $\mathrm{pCO}_{2}$ $31 \mathrm{mmHg}, \mathrm{pO}_{2} 116 \%, \mathrm{HCO}_{3}{ }^{-} 20.1 \mathrm{mmol} / \mathrm{L}$, $\mathrm{SaO}_{2} 99 \%$, BMP: sodium $145 \mathrm{mmol} / \mathrm{L}$, potassium $3.7 \mathrm{mmol} / \mathrm{L}$, chloride $110 \mathrm{mmol} / \mathrm{L}$, bicarbonate $16 \mathrm{mmol} / \mathrm{L}$, anion gap $19 \mathrm{mmol} / \mathrm{L}, \mathrm{BUN}$ $24 \mathrm{mg} / \mathrm{dL}$, creatinine $0.77 \mathrm{mg} / \mathrm{dL}$, glucose $366 \mathrm{mg} / \mathrm{dL}$, repeat ECG showed normalized T waves.

The patient also presented with abdominal pain on admission. Initially, this pain was diagnosed as DKA-associated abdominal pain. However, she had persistent abdominal pain despite the closure of the anion gap and correction of DKA and HHS. Additional laboratory tests revealed lipase $720 \mathrm{U} / \mathrm{L}$ and amylase $225 \mathrm{U} / \mathrm{L}$, suggesting acute pancreatitis. CT of abdomen and pelvis without contrast found mild-moderate right-sided hydronephrosis and hydroureter down to the level of a 6-mm stone in the proximal-mid right ureter without 
significant pancreatic changes. MRCP showed no biliary or pancreatic duct dilation. Current diagnostic criteria of acute pancreatitis require two out of three of the following criteria: (1) acute abdominal pain and tenderness in the upper abdomen; (2) elevated levels of pancreatic enzymes in the blood or urine; (3) abnormal finding of acute pancreatitis detected by ultrasound, CT, or MRI [8]. Of note, imaging studies are not $100 \%$ sensitive and in mild episodes of acute pancreatitis, CT features can range from normal-appearing pancreas to diffuse enlargement and heterogeneous attenuation of the gland $[8,9]$. Taken together, this patient was diagnosed with acute pancreatitis, although the etiology was initially unknown.

After this sentinel episode of acute pancreatitis, she developed four additional episodes of recurrent non-DKA-associated acute pancreatitis with lipase elevations to 201, 163, 266, and $2495 \mathrm{U} / \mathrm{L}$. Autoimmune pancreatitis workup was negative, including pancreatic elastase $>500 \mu \mathrm{g} / \mathrm{g}$, ANA negative, IgG4 $32.5 \mathrm{mg} / \mathrm{dL}$ (normal 4.0-86.0). As a result of recurrent acute pancreatitis, the patient underwent ERCP, with findings suggestive of sphincter of Oddi dysfunction, and subsequently underwent sphincterotomy, without additional pancreatitis episodes afterwards. Thus, the patient's pancreatitis was likely caused by sphincter of Oddi dysfunction, with possible contributions from NSAIDs use; meloxicam can cause pancreatic duct constriction through prostaglandin inhibition $[10,11]$.

This patient's abdominal pain was initially mistakenly attributed to DKA. It has been reported that DKA can induce abdominal pain in $40-75 \%$ cases and the severity can mimic acute abdomen, thus masking and delaying diagnosis of the underlying etiology $[12,13]$. DKA can also induce leukocytosis [1] and cause nonspecific amylase and lipase elevation $[12,14,15]$, thus making it challenging to differentiate DKA from acute pancreatitis.

To facilitate the differential diagnosis, it has been reported that the severity of DKA-related abdominal pain is associated with the severity of the metabolic acidosis, but not with the severity of hyperglycemia or dehydration. Importantly, when the metabolic acidosis is corrected, the abdominal pain usually resolves [12]. If the abdominal pain persists despite correction of the metabolic acidosis, like this case, then there should be a systematic investigation of the underlying etiology. Other abdominal pathologies that present with abdominal pain and can be DKA triggers include urinary tract infection, pyelonephritis, perforated viscus, and appendicitis $[12,13]$.

The mechanisms of acute pancreatitis-triggered hyperglycemia and DKA are (1) pancreatitis affects insulin secretion [16], and (2) pancreatitis induces a systemic inflammatory response, which triggers a sympathetic response with increased cortisol, adrenaline, glucagon, and growth hormone release, thereby worsening insulin resistance. Subsequently, these changes promote lipolysis, free fatty acid release from adipose tissue, and hepatic ketone formation, leading to the development of hyperglycemia, ketoacidosis, dehydration, and DKA and HHS (Fig. 1).

It has been reported that acute pancreatitis can induce hyperglycemia and DKA [15, 17], and diabetes can be an independent risk factor for acute pancreatitis [15, 18]. However, a patient with stable prediabetes, like our case, is unlikely to rapidly deteriorate into DKA and HHS without a trigger. It is most likely that her acute pancreatitis led to hyperglycemia and then DKA and HHS. Therefore, clinicians should be vigilant and consistently search for underlying triggers that cause patients to enter into a diabetic crisis. Equally important, when managing patients with acute pancreatitis, physicians should pay particular attention to metabolic profiles for early detection of glycemic derangement and prompt treatment $[19,20]$.

As mentioned previously, this patient had a history of glucose intolerance in pregnancy [21], occasional mildly elevated fasting glucose, and $\mathrm{HbA} 1 \mathrm{c}$ of $6.4 \%$ on admission, all of which are consistent with preadmission prediabetes. However, the deterioration directly from preadmission prediabetes into clinical diabetes on admission with DKA and HHS $[1,21]$ is a less recognized clinical phenomenon, suggesting an atypical form of diabetes called ketosis-prone diabetes [3]. The clinical characteristics of 


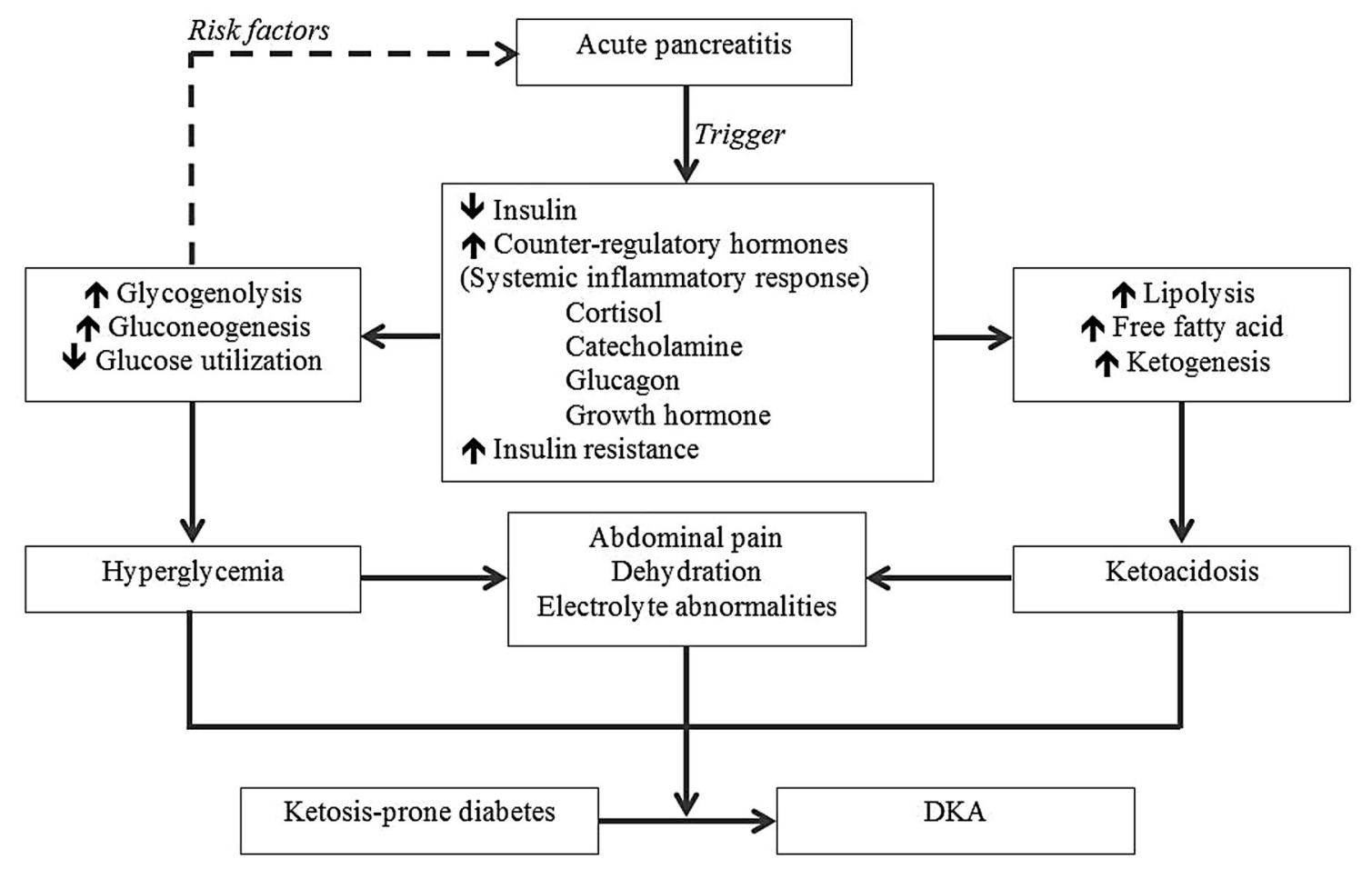

Fig. 1 Interrelationship between acute pancreatitis and hyperglycemic crisis

ketosis-prone diabetes include adult onset, insulin resistance, stress-precipitated DKA, and unprovoked ketosis [3, 22]. The most useful classification is based on the presence of pancreatic autoantibody (autoantibody present, $\mathrm{A}+$; absent, $\mathrm{A}-$ ) and preservation of beta cell function (beta cell function preserved, $\beta+$; absent, $\beta-$ ) and divides ketosis-prone diabetes into four categories (A $\beta$ classification): $A+\beta+$, $A-\beta+, A+\beta-$, and $A-\beta-$. The etiology is thought to be beta cell destruction or dysfunction, although the exact mechanism requires further investigation. The $A \beta$ classification of ketosis-prone diabetes has been proven to be highly accurate and predictive of glycemic control and insulin requirement, and it is recommended that the classification of ketosisprone diabetes be performed at the first outpatient visit 1-3 weeks after hospital discharge [3, 23].

After DKA episodes, some ketosis-prone diabetic patients are able to discontinue insulin and maintain adequate glycemic control with oral agents only $[3,23]$. This patient, post-discharge, was continued on basal plus pre- prandial insulin therapy with good insulin compliance. Further testing revealed negative pancreatic autoantibodies including islet cell autoantibody $<5$ JDF units and glutamic acid decarboxylase (GAD)-65 antibody $<5 \mathrm{IU} / \mathrm{mL}$. She eventually developed overt diabetes with HbA1c from the initial $6.4 \%$ on admission to $6.7 \% 2$ weeks later to $8.6 \% 7$ months later and $9.0 \%$ most recently at 15 months, indicating the gradual loss of beta cell function and absolute insulin insufficiency. Therefore, she was classified as $A-\beta$ - type. Because of her labile diabetes, the patient was started on insulin pump therapy.

\section{CONCLUSION}

DKA and HHS are common clinical presentations that require clinical considerations beyond the well-established protocol-guided treatment of metabolic derangements. First, in addition to early initiation of IV fluid and IV insulin therapy, clinicians should search for and treat the triggers in order to achieve more 
favorable outcomes. Second, DKA can produce abdominal pain mimicking acute abdomen and thus delay the diagnosis of the underlying etiology. Clinicians should be vigilant and consider a broad differential diagnosis, with special consideration for pathologies that can cause both abdominal pain and trigger DKA. Third, prediabetes can directly evolve into DKA, which is a less recognized clinical phenomenon and represents an atypical type of diabetes called ketosis-prone diabetes. These patients should be closely followed since they require early recognition, appropriate $A \beta$ classification, and prompt insulin treatment to prevent the deterioration into diabetic crises, especially under stressful conditions.

\section{ACKNOWLEDGEMENTS}

The authors are very grateful to the patient for her kind contribution to this study.

Funding. No funding or sponsorship was received for this study or publication of this article.

Authorship. All named authors meet the International Committee of Medical Journal Editors (ICMJE) criteria for authorship for this article, take responsibility for the integrity of the work as a whole, and have given their approval for this version to be published.

Disclosures. Runbo Song and Shanjin Cao have nothing to disclose.

Compliance with Ethics Guidelines. All procedures performed in the study were in accordance with the ethical standards of the institutional and/or national research committee and with the 1964 Declaration of Helsinki and its later amendments or comparable ethical standards. Informed consent was obtained from the individual participant for being included in the study.

Data Availability. All data generated or analyzed during this study are included in this published article.
Open Access. This article is distributed under the terms of the Creative Commons Attribution-NonCommercial 4.0 International License (http://creativecommons.org/licenses/ by-nc/4.0/), which permits any noncommercial use, distribution, and reproduction in any medium, provided you give appropriate credit to the original author(s) and the source, provide a link to the Creative Commons license, and indicate if changes were made.

\section{REFERENCES}

1. Kitabchi AE, Umpierrez GE, Miles JM, Fisher JN. Hyperglycemic crises in adult patients with diabetes. Diabetes Care. 2009;32(7):1335-43.

2. Corwell B, Knight B, Olivieri L, Willis GC. Current diagnosis and treatment of hyperglycemic emergencies. Emerg Med Clin N Am. 2014;32(2):437-52.

3. Balasubramanyam A, Nalini R, Hampe CS, Maldonado M. Syndromes of ketosis-prone diabetes mellitus. Endocr Rev. 2008;29(3):292-302.

4. Tsapenko MV. Modified delta gap equation for quick evaluation of mixed metabolic acid-base disorders. Oman Med J. 2013;28(1):73-4.

5. Galla JH. Metabolic alkalosis. J Am Soc Nephrol. 2000;11(2):369-75.

6. Hyperkalaemia in diabetic ketoacidosis. Lancet. 1986;2(8511):845-6.

7. Adrogue HJ, Lederer ED, Suki WN, Eknoyan G. Determinants of plasma potassium levels in diabetic ketoacidosis. Medicine (Baltimore). 1986;65(3):163-72.

8. Kiriyama S, Gabata T, Takada T, et al. New diagnostic criteria of acute pancreatitis. J Hepatobiliary Pancreat Sci. 2010;17(1):24-36.

9. Koo BC, Chinogureyi A, Shaw AS. Imaging acute pancreatitis. Br J Radiol. 2010;83(986):104-12.

10. Tenner S, Baillie J, DeWitt J, Vege SS, American College of Gastroenterology. American College of Gastroenterology guideline: management of acute pancreatitis. Am J Gastroenterol. 2013;108(9):1400-15 (1416).

11. Hung WY, Abreu Lanfranco O. Contemporary review of drug-induced pancreatitis: a different 
perspective. World J Gastrointest Pathophysiol. 2014;5(4):405-15.

12. Umpierrez G, Freire AX. Abdominal pain in patients with hyperglycemic crises. J Crit Care. 2002;17(1):63-7.

13. Margekar SL, Jayant SS, Jatav OP, Jain M, Chouksey A. Abdominal pain in diabetes-DKA is not the only cause. J Assoc Physicians India. 2014;62(5):450-1.

14. Song R, Cao S. Post-bariatric surgery starvation ketoacidosis and lipase elevation in the absence of DKA or pancreatitis. Am J Emerg Med. 2018;36(3):525.e3-5.

15. Nair S, Yadav D, Pitchumoni CS. Association of diabetic ketoacidosis and acute pancreatitis: observations in 100 consecutive episodes of DKA. Am J Gastroenterol. 2000;95(10):2795-800.

16. Solomon SS, Duckworth WC, Jallepalli P, Bobal MA, Iyer R. The glucose intolerance of acute pancreatitis: hormonal response to arginine. Diabetes. 1980;29(1):22-6.

17. Reghina AD, Craciun S, Fica S. Severe transient hyperglycemia in a prediabetic patient during mild acute pancreatitis. Case Rep Med. 2015;2015:968593.
18. Noel RA, Braun DK, Patterson RE, Bloomgren GL. Increased risk of acute pancreatitis and biliary disease observed in patients with type 2 diabetes: a retrospective cohort study. Diabetes Care. 2009;32(5):834-8.

19. Samad A, James A, Wong J, et al. Insulin protects pancreatic acinar cells from palmitoleic acid-induced cellular injury. J Biol Chem. 2014;289(34):23582-95.

20. Li J, Chen TR, Gong HL, Wan MH, Chen GY, Tang WF. Intensive insulin therapy in severe acute pancreatitis: a meta-analysis and systematic review. West Indian Med J. 2012;61(6):574-9.

21. American Diabetes Association. 2. Classification and diagnosis of diabetes: standards of medical care in diabetes-2018. Diabetes Care. 2018;41(Suppl 1):S13-27.

22. Liu B, Yu C, Li Q, Li L. Ketosis-onset diabetes and ketosis-prone diabetes: same or not? Int J Endocrinol. 2013;2013:821403.

23. Safder SB, Mortada R. Diabetes 1.5: ketone-prone diabetes. Clin Diabetes. 2015;33(3):150-1. 